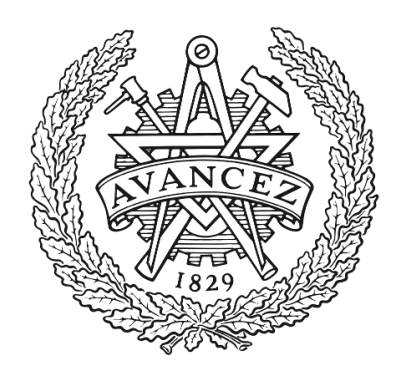

\title{
CHALMERS
}

UNIVERSITY OF TECHNOLOGY

\section{Online and On-Board Battery Impedance Estimation of Battery Cells, Modules or Packs in a Reconfigurable Battery System or Multilevel}

Downloaded from: https://research.chalmers.se, 2023-04-26 07:29 UTC

Citation for the original published paper (version of record):

Kersten, A., Kuder, M., Han, W. et al (2020). Online and On-Board Battery Impedance Estimation of Battery Cells, Modules or Packs in a

Reconfigurable Battery System or Multilevel Inverter. IECON Proceedings (Industrial Electronics Conference): 1884-1891. http://dx.doi.org/10.1109/IECON43393.2020.9254515

N.B. When citing this work, cite the original published paper. 


\title{
Online and On-Board Battery Impedance Estimation of Battery Cells, Modules or Packs in a Reconfigurable Battery System or Multilevel Inverter
}

\author{
Anton Kersten ${ }^{1}$, Student Member, IEEE, Manuel Kuder ${ }^{2}$, Weiji $\mathrm{Han}^{1}$, Member, IEEE, \\ Torbjörn Thiringer ${ }^{1}$, Senior Member, IEEE, Anton Lesnicar ${ }^{2}$, Thomas Weyh ${ }^{2}$, and Richard Eckerle ${ }^{2}$ \\ ${ }^{1}$ Chalmers University of Technology, Department of Electrical Engineering, Gothenburg, Sweden \\ Email: kersten@chalmers.se \\ ${ }^{2}$ Bundeswehr University Munich, Department of Electrical Engineering, Neubiberg, Germany \\ Email: manuel.kuder@unibw.de
}

\begin{abstract}
This paper shows two approaches to determine the battery impedance of battery cells or battery modules when used in a reconfigurable battery system (RBS) or in any type of modular multilevel converter (MMC) for electric drive applications. A generic battery model is used and the concepts of the recursive time and frequency-domain parameter extraction, using a current step and an electrochemical impedance spectroscopy, are explained. Thus, it is shown and demonstrated that the balancing current of neighboring cells/modules, when in parallel operation, can be used, similar to the time-domain parameter extraction utilizing a current step, to determine the battery parameters. Furthermore, it is shown and demonstrated that a part of the inverter can be used as variable $\mathrm{AC}$ voltage source to control a sinusoidal current through the motor inductances of the drive train, which can be injected to the inserted battery cells/modules of an adjacent phase to perform an on-board impedance spectroscopy. Using either of the two presented approaches, the individual battery impedances can be easily determined, yielding the state of health (SOH) and the power capability of individual battery cells/modules. Nonetheless, the analyzed approaches were just considered to be applied at machine standstill, which is not suitable for grid-tied applications.
\end{abstract}

Index Terms-Batteries, Electrochemical impedance spectroscopy, Modular multilevel converters, Multilevel systems, Parameter estimation.

\section{INTRODUCTION}

Modular multilevel converter or reconfigurable battery system topologies are gaining in interest within the field of transportation electrification or electric energy storage systems. Multilevel converters, in comparison to classical twolevel converters, have several advantages as for example fault tolerant operation [1]-[3], increased drive cycle or partial load efficiency, when using low voltage MOSFETs in comparison to common IGBT solutions [4]-[9], and reduced electromagnetic emissions (EME) [10]-[12]. Nevertheless, due the cascaded or interleaved structure of the converter, the integrated battery packs are stressed with additional low order harmonic components, which reduces the battery efficiency in comparison to a classical two-level converter system [6], [13], [14]. It is often controversially discussed that these low order harmonics can cause a rapid aging of the battery cells, which has been proven to be wrong in [15], [16]. Integrating the power electronics even on cell or small battery pack level, the converter can additionally act as a part of the battery management system (BMS) [16]-[18], sometimes referred to as a reconfigurable battery system [17]-[19]. Using a multilevel converter with integrated batteries or an RBS drive train topology, each battery cell/module can be drained according to its individual capacity. In this manner the battery can be fully utilized even if individual battery cells have a reduced state of health. This in turn increases the actual life time of the drive train, since common traction batteries are typically replaced if the SOH drops below $80 \%$. However, an RBS typically needs an additional, dedicated propulsion inverter.

For two-level inverter drives, different algorithms to trigger battery faults [20] or to monitor the battery pack's state of health and state of charge (SOC) [21], [22] can be found. Furthermore, detailed analysis for the recursive parameter extraction of a generic electric impedance model [23]-[27] in time [27]-[31] and frequency-domain [27], [32], [33] can be found. Especially, the battery's impedance is of interest, since it indicates power capability and state of health [34], [35]. Nonetheless, a common battery pack consists of hardwired connections, which make an impedance determination and replacement of weak or faulty battery cells complicated, which is indeed an advantage of multilevel converter or RBS topologies. In [36] the SOHs of individual battery packs are determined and balanced over time to increase the life time of the drive system.

However, missing in the entire previously mentioned literature is the battery impedance determination of individual 


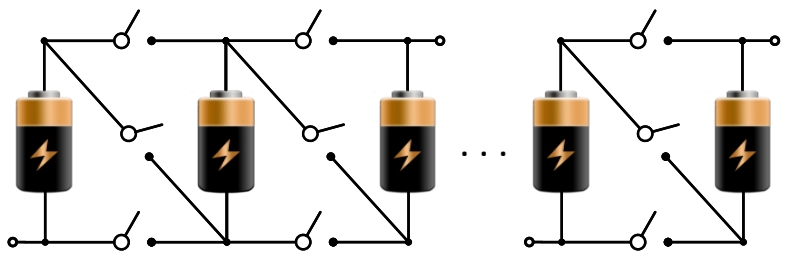

(a)

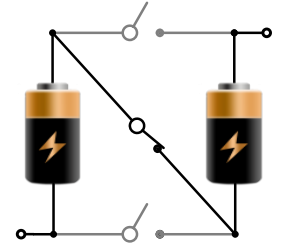

(b)

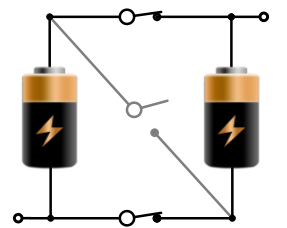

(c)

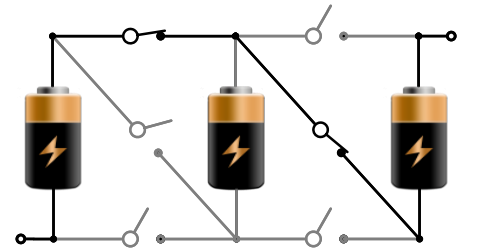

(d)

Fig. 1: (a) Arrangement and working principle of the reconfigurable battery BM3 system with flexible series and parallel connections of battery cells: (b) series connection, (c) parallel connection and (d) bypass connection.

battery cells/modules of RB or multilevel drive systems. Therefore, this paper introduces the application of two diagnostic approaches to determine the impedance of battery cells/modules when used in an RB or multilevel drive system without needing any additional hardware. The first approach utilizes the balancing current when a parallel operation is triggered between adjacent battery cells/modules. The second approach, rearranges the inverter and traction motor so that an online impedance spectroscopy can be carried out. Both methods are validated by experiments and simulations.

\section{Reconfigurable Battery AND Multilevel CONVERTER SYSTEM}

In literature, several RB [17]-[19] or multilevel converter systems [37]-[39] can be found.

For example, the RBS topology shown and described in Fig. 1, referred to as battery modular multilevel management (BM3) [16], [40] system, can be used to dynamically alter the connections between adjacent battery cells/modules. In this way, parallel or series connections can be dynamically formed or individual cells can be bypassed. In this way, a dedicated BMS becomes obsolete. An RBS is normally operated with an additional, dedicated propulsion inverter. Using one strand per phase, the BM3 topology could even be applied as a propulsion converter, similar to the cascaded H-bridge $(\mathrm{CHB})$ [41], [42] or the M2B/MMSP [6], [43] converter, shown in Fig. 2. In comparison to an RBS, a multilevel converter utilizes dedicated battery packs with a moderate number of series

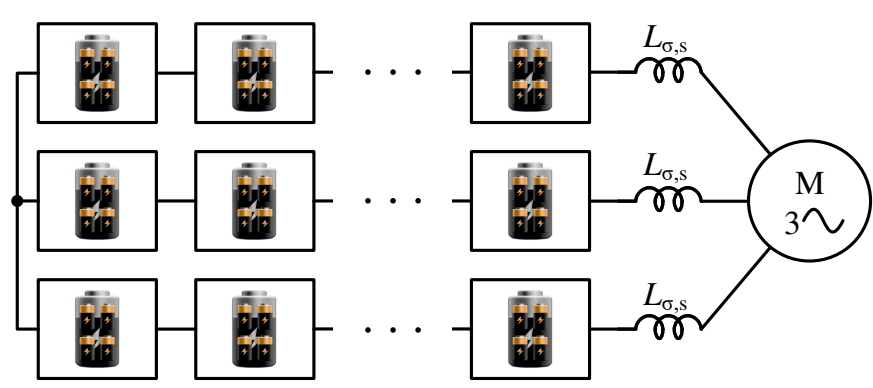

(a)

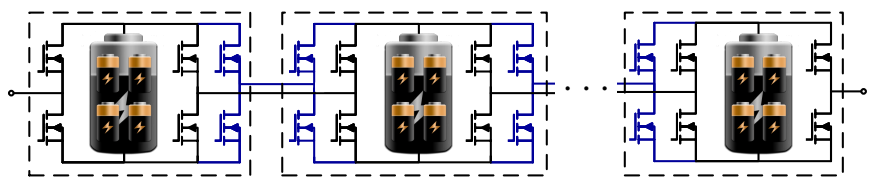

(b)

Fig. 2: (a) Structure of the CHB or M2B/MMSP multilevel inverter topology for a drive application with the motor's stator inductance $L_{\sigma}$, s and (b) submodule arrangement of the CHB inverter and additional half-bridges of the M2B/MMSP topology emphasized in blue.

connected battery cell strings. Thus, each battery pack is equipped with a passive balancing circuit. Due to the limited number of series connected battery cells, the balancing effort is not as large as for high voltage battery packs. The shown CHB converter can dynamically insert the battery packs in forward or reverse direction and these could also be bypassed. In this manner any kind of phase output voltage waveform can be achieved. Additionally, the M2B/MMSP converter can parallelize battery modules to reduce the battery losses.

Within the frame of this paper's analysis just the two mentioned topologies are considered. However, the in the following described algorithms can be easily adapted to several types of multilevel converter or RB systems.

\section{BATTERY MODELING}

Several battery equivalent circuit models, based on RC-networks, can be found in [23]-[27]. The Randles model, as can be seen in Fig. 3, seems to be the most suitable to describe the electric dynamics of the battery. With the help of the battery impedance the maximum power limit of the battery cell can be determined and, as a function over time, the battery aging can be assessed. Furthermore, as described in [13] and [6], simple energy calculations can be performed using the equivalent circuit models.

The impedance of the Randles model in the s-domain can be mathematically described as

$$
\bar{Z}_{\text {Cell }}(s)=R_{0}+\frac{R_{1}}{s+R_{1} C_{1}}+\ldots+\frac{R_{\mathrm{n}}}{s+R_{\mathrm{n}} C_{\mathrm{n}}}+s L_{\sigma, \mathrm{b}} .
$$

When neglecting the stray inductance $L_{\sigma, \mathrm{b}}$, (1) can be rewritten in transfer function form as

$$
\bar{Z}_{\text {Cell }}(s)=\frac{b_{n} s^{n}+b_{n-1} s^{n-1}+\ldots+b_{1} s+b_{0}}{s^{n}+a_{n-1} s^{n-1}+\ldots+a_{1} s+a_{0}} .
$$




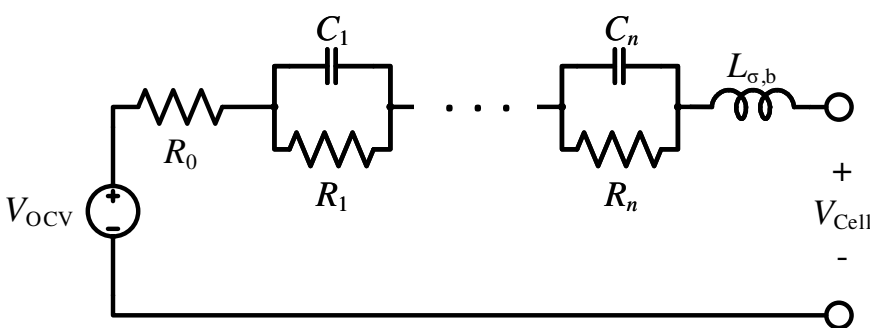

Fig. 3: Generalized Randles model of a battery cell's impedance including the stray inductance $L_{\sigma, \mathrm{b}}$.

Using its corresponding poles, $p=\left\{p_{n}, p_{n-1}, p_{n-2} \ldots p_{1}\right\}$, and zeros, $z=\left\{z_{n}, z_{n-1}, z_{n-2} \ldots z_{1}\right\}$, the cell impedance term becomes

$$
\bar{Z}_{\text {Cell }}(s)=b_{n} \frac{\left(s-z_{n}\right)\left(s-z_{n-1}\right) \ldots\left(s-z_{1}\right)}{\left(s-p_{n}\right)\left(s-p_{n-1}\right) \ldots\left(s-p_{1}\right)} .
$$

The selection of the number of RC-links $n$ depends on the actual application to be described by the model. For example, as described in [13], when used for energy calculations of $\mathrm{CHB}$ propulsion inverters it can be reasonable to choose up to three RC pairs.

\section{ReCursive TIME-DOMAin BATtery PARAMEter EXTRACTION USING CURRENT AND VolTage WAVEForm}

\section{A. Parameter Extraction using a Pulsed Current}

A common way to determine the parameters of the transfer function in (3) is the time-domain parameter extraction using the current and voltage waveforms of the battery cell under test, as for example described in [27]-[29]. Using an adaptive control approach, the determination can be directly applied during the operation of the vehicle [30]. However, due to the dynamics of the drive train it might be more suitable to apply just a defined current step during stand-still. Hence, the transfer function can easily be parametrized using a generic least-square fit approach. Numerical computer tools, such as MATLAB's curve fitting toolbox, can be used. The equivalent circuit parameters, neglecting the stray inductance and using three RC pairs, can then be extracted as described in the following. From the poles, the system's time constants can be calculated according to

$$
\left[\begin{array}{l}
\tau_{1} \\
\tau_{2} \\
\tau_{3}
\end{array}\right]=-\left[\begin{array}{l}
1 / p_{1} \\
1 / p_{2} \\
1 / p_{3}
\end{array}\right]
$$

Knowing the time constants, a matrix $A$ can be created according to

$$
A=\frac{1}{\tau_{1} \tau_{2} \tau_{3}} \cdot\left[\begin{array}{cccc}
\tau_{1} \tau_{2} \tau_{3} & 0 & 0 & 0 \\
\tau_{1} \tau_{2}+\tau_{1} \tau_{3}+\tau_{2} \tau_{3} & \tau_{2} \tau_{3} & \tau_{1} \tau_{3} & \tau_{1} \tau_{2} \\
\tau_{1}+\tau_{2}+\tau_{3} & \tau_{2}+\tau_{3} & \tau_{1}+\tau_{3} & \tau_{1}+\tau_{2} \\
1 & 1 & 1 & 1
\end{array}\right]
$$

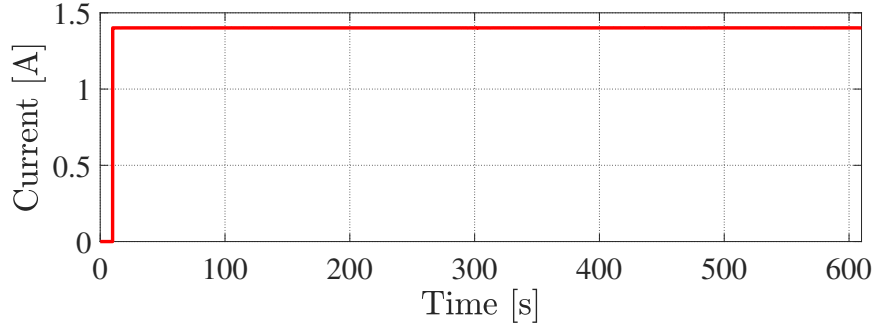

(a)

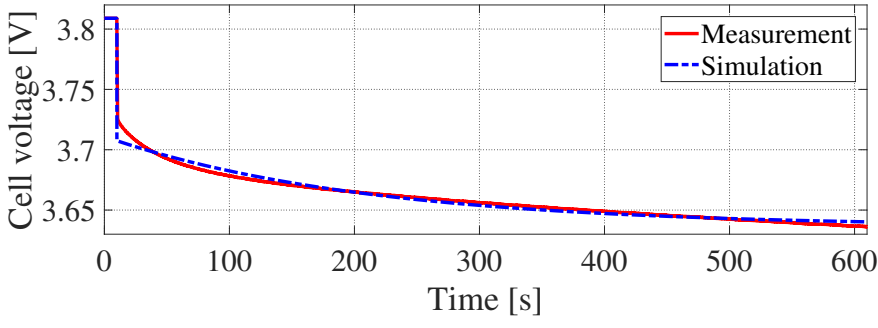

(b)

Fig. 4: Battery cell parameter extraction using a pulsed current: observed (a) current step and (b) battery cell's voltage drop.

which can be used to calculate the equivalent circuit resistances as

$$
\left[\begin{array}{l}
R_{0} \\
R_{1} \\
R_{2} \\
R_{3}
\end{array}\right]=A^{-1}\left[\begin{array}{l}
b_{3} \\
b_{2} \\
b_{1} \\
b_{0}
\end{array}\right] .
$$

The capacitances can now be calculated as

$$
\left[\begin{array}{l}
C_{1} \\
C_{2} \\
C_{3}
\end{array}\right]=\left[\begin{array}{ccc}
\tau_{1} & 0 & 0 \\
0 & \tau_{2} & 0 \\
0 & 0 & \tau_{3}
\end{array}\right]\left[\begin{array}{l}
1 / R_{1} \\
1 / R_{2} \\
1 / R_{3}
\end{array}\right]
$$

If the Randles model is used with two or one time constants, the parameters can be calculated in a similar way from the least-square fit.

For example, Fig. 4(a) shows a $0.5 \mathrm{C}$ pulse applied to a single 18650 battery cell ([44]). Meanwhile, the battery voltage drop is monitored as depicted in Fig. 4(b) in red. Using MATLAB's system identification toolbox and, for simplification, considering just one RC pair, the cell impedance was determined to be

$$
\bar{Z}_{\text {Cell }}(s)=\frac{0.07251 s+0.0005935}{s+0.004811}
$$

which can be rearranged to the pole-zero form as

$$
\bar{Z}_{\text {Cell }}(s)=0.07251 \frac{s+0.0082}{s+0.004811} .
$$

Thus, the time constant $\tau_{1}$ can be calculated using the system pole as

$$
\tau_{1}=-\frac{1}{p_{1}}=207.86 \mathrm{~s}
$$

and the $A$-matrix becomes

$$
A=\frac{1}{\tau_{1}} \cdot\left[\begin{array}{cc}
\tau_{1} & 0 \\
1 & 1
\end{array}\right]
$$




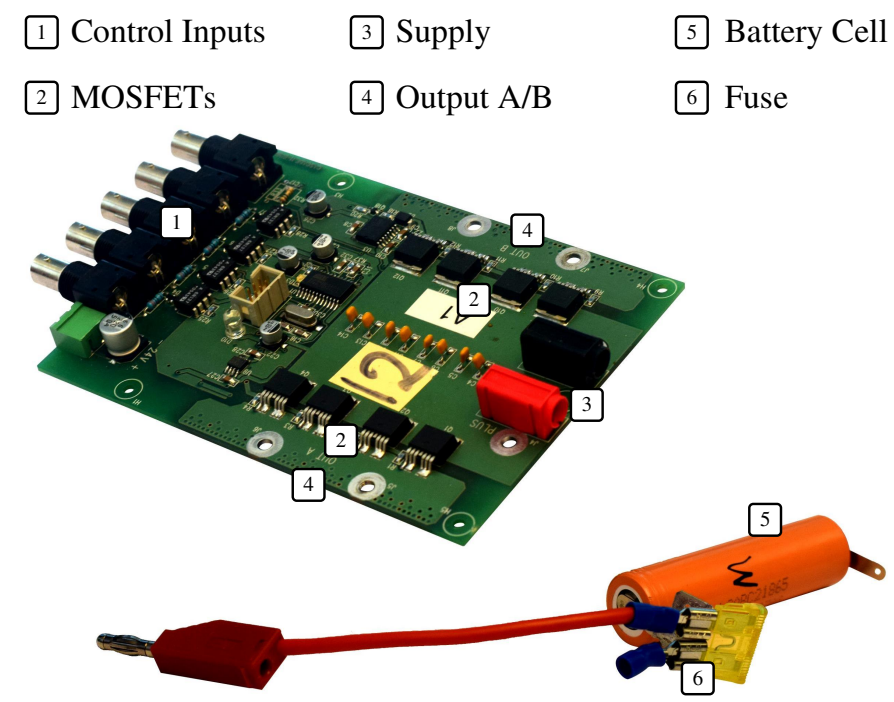

Fig. 5: Used H-bridge module and battery cell with fuse.

Consequently, the equivalent circuit resistances can be calculated as follows:

$$
\begin{gathered}
{\left[\begin{array}{l}
R_{0} \\
R_{1}
\end{array}\right]=A^{-1}\left[\begin{array}{l}
b_{1} \\
b_{0}
\end{array}\right]=\left[\begin{array}{cc}
1 & 0 \\
-1 & \tau_{1}
\end{array}\right]\left[\begin{array}{l}
b_{1} \\
b_{0}
\end{array}\right]} \\
R_{0}=b_{1}=72.5 \mathrm{~m} \Omega \\
R_{1}=b_{0} \tau_{1}-b_{1}=51 \mathrm{~m} \Omega
\end{gathered}
$$

Last, the equivalent circuit capacitance can be calculated as

$$
C_{1}=\frac{\tau_{1}}{R_{1}}=4.08 \mathrm{kF} .
$$

The simulated voltage drop, using the extracted parameters, can be seen in Fig. 4(b) in blue. Due to the selection of just one RC pair, the simulated voltage drop slightly differs from the measurement in the beginning of the current step.

\section{B. Parameter Extraction using Balancing Current}

Considering the multilevel inverter or reconfigurable battery system topologies as shown in Figs. 1 and 2, the battery parameters can be extracted using the balancing current between battery cells/modules when in parallel operation.

As a short recap, in case of different SOCs of neighboring battery cells or modules, a difference in their battery voltages can be observed. Thus, when paralleling batteries with different SOCs, charges, in form of an electric current, are automatically transferred from the battery cell/module with the higher SOC to the one with the lower SOC. Similar as for an applied current pulse, with the help of the monitored balancing current and the battery voltages the transfer function in (1) can be parameterized.

To demonstrate this approach, a laboratory, small-scale setup of a reconfigurable battery system, as show in Fig. 1, was built. For the small-scale setup the H-bridges and battery cells ([44]) as shown in Fig. 5 are used. Two H-bridges,

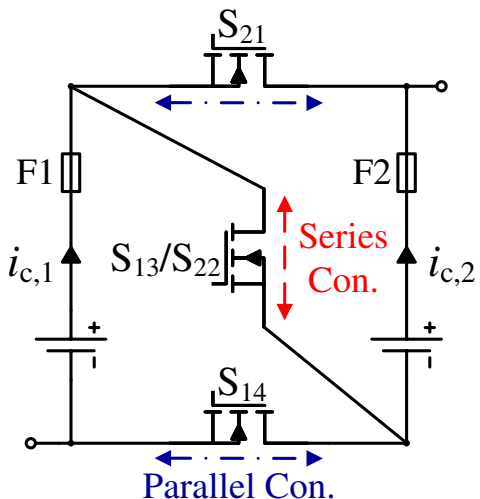

(a)

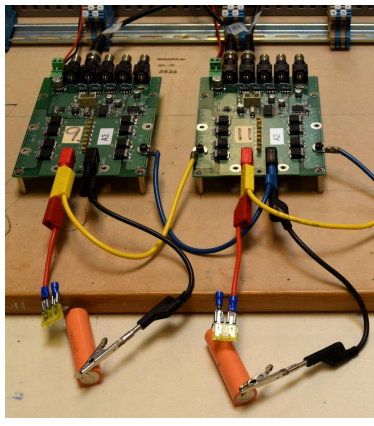

(b)
Fig. 6: (a) Schematic H-bridge arrangement of adjacent cells to achieve an RBS topology and (b) laboratory, small-scale setup.

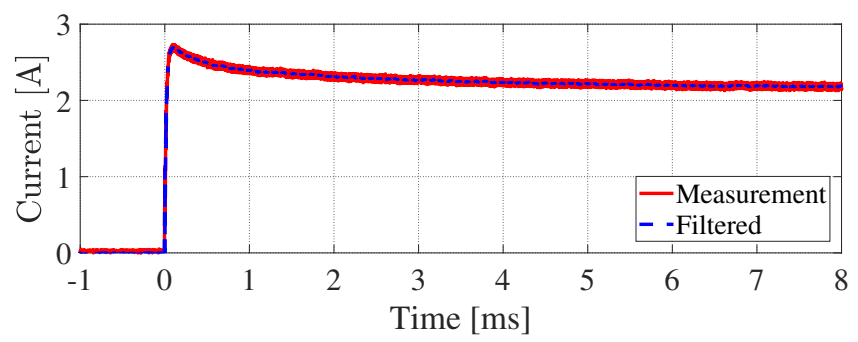

(a)

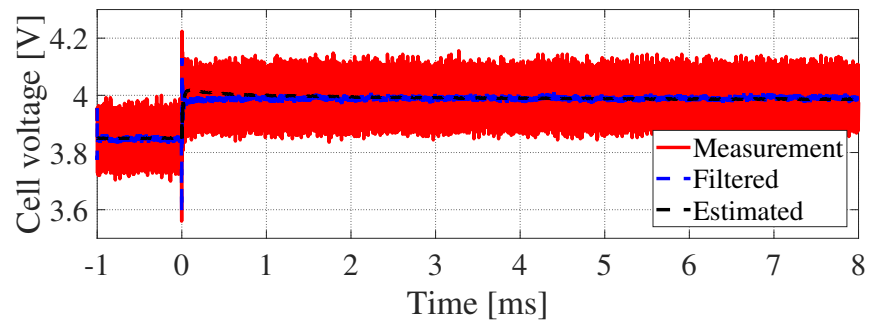

(b)

Fig. 7: (a) Balancing current between adjacent battery cells (initially, $V_{\mathrm{Cell}, 1}=3.85 \mathrm{~V}$ and $V_{\mathrm{Cell}, 2}=4.14 \mathrm{~V}$ ) and (b) monitored battery cell voltage of battery cell number one and simulated battery voltage using the extracted parameters. Extracted Parameters: $R_{0}=62.5 \mathrm{~m} \Omega ; R_{1}=60.1 \mathrm{~m} \Omega$ and $C_{1}=3.42 \mathrm{kF}$.

each equipped with one battery cell, were connected as schematically depicted in Fig. 6(a). The actual laboratory setup can be seen in Fig. 6(b). During a simple test, the battery cells were switched from the series to the parallel connection. The waveform of the measured balancing current, when paralleling both battery cells (initially, $V_{\text {Cell, } 1}=3.85 \mathrm{~V}$ and $V_{\text {Cell,2 }}=4.14 \mathrm{~V}$ ), can be seen in Fig. 7(a). It should be noted that the battery current flows from the second to the first cell. The current looks similar to a proper current step, except for the overshoot in the beginning. Furthermore, the measured battery voltage of cell number one can be seen in Fig. 7(b). Due to the noise of the voltage probe, the voltage 


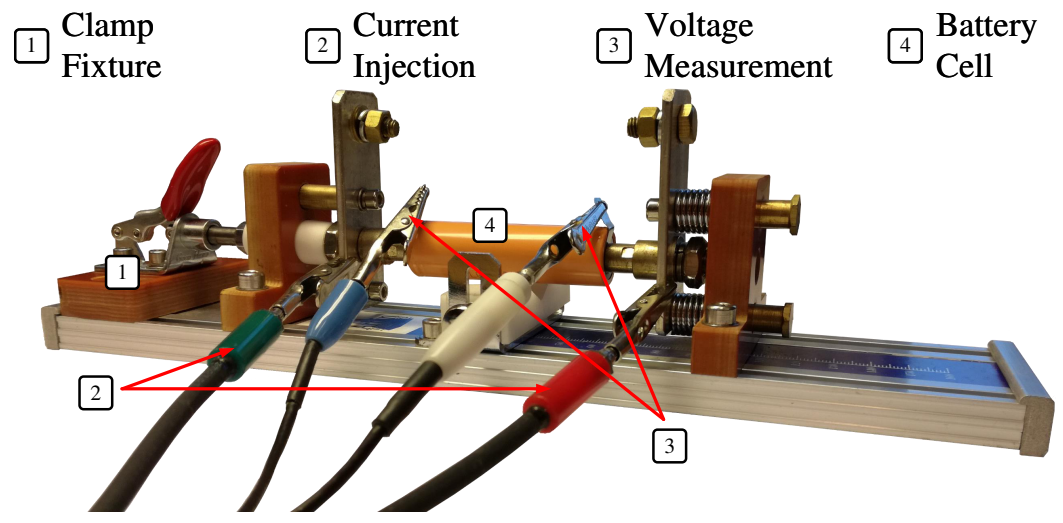

(a)

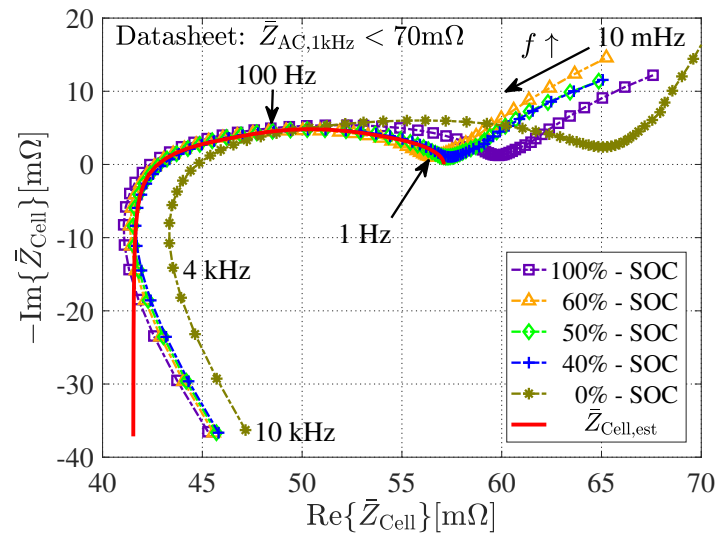

(b)

Fig. 8: (a) Battery cell test fixture and (b) impedance plot of the high energy cell for different SOCs [6].

TABLE I: Battery cell parameters extracted from EIS [6] (shown in Fig. 8(b) in red)

\begin{tabular}{cccccccc}
\hline \hline $\mathrm{R} 0[\mathrm{~m} \Omega]$ & $\mathrm{R} 1[\mathrm{~m} \Omega]$ & $\mathrm{R} 2[\mathrm{~m} \Omega]$ & $\mathrm{R} 3[\mathrm{~m} \Omega]$ & $\mathrm{C} 1[\mathrm{mF}]$ & $\mathrm{C} 2[\mathrm{mF}]$ & $\mathrm{C} 3[\mathrm{~F}]$ & $L_{\sigma, \mathrm{b}}[\mathrm{nH}]$ \\
\hline 41.53 & 5.02 & 7.32 & 3.23 & 75.44 & 339.5 & 3.625 & 590.8 \\
\hline \hline
\end{tabular}

signal needed to be filtered. Again, using MATLAB's system identification toolbox, similar as described in (8) to (12), the equivalent circuit parameters of the battery were determined as

$$
R_{0}=62.5 \mathrm{~m} \Omega ; R_{1}=60.1 \mathrm{~m} \Omega \text { and } C_{1}=3.42 \mathrm{kF}
$$

Consequently, using (16), the battery voltage was simulated as can be seen in Fig. 7(b) in black (dashed). Similar as for the before analyzed current step response, the model using just one RC pair slightly overestimates the voltage swing during the switching transient, while the steady state voltage drop is accurately estimated. The proposed technique can be easily extended to multiple RC pairs.

Nonetheless, the basic principle of the battery parameter estimation using the balancing current between battery cells/modules could be validated. Consequently, the presented estimation approach could be implemented for any multilevel inverter or reconfigurable battery system, which allows for dynamic paralleling of battery cells/modules.

\section{FRequency-Domain BATtery PARAMETER EXTRACTION USING IMPEDANCE SPECTROSCOPY}

\section{A. Parameter Extraction using Impedance Spectroscopy}

Another way to extract the equivalent circuit parameters of a battery cell/module is the electrochemical impedance spectroscopy (EIS), which is extensively covered in [27], [32] and [33]. For this method, a sinusoidal current with a certain frequency is injected into the battery cell/module, while the battery cell/module voltage oscillation is monitored. Thus, the impedance for the selected frequency can be calculated using the relation of the injected current, monitored voltage and their phase shift. Using a frequency sweep, the impedance can be determined for a broad frequency range. For example, Fig. 8 shows an EIS performed at a single battery cell ([44]) using

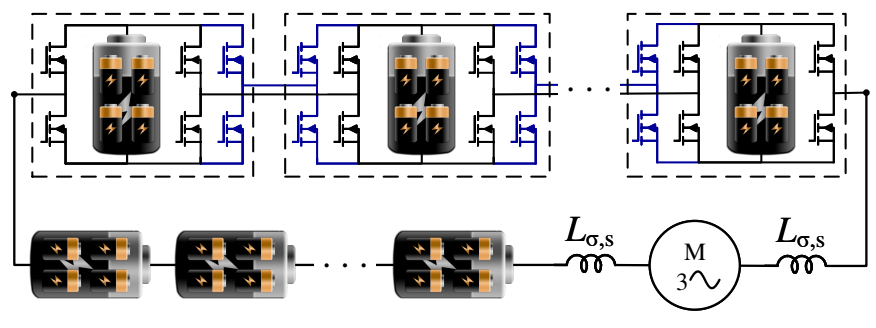

(a)

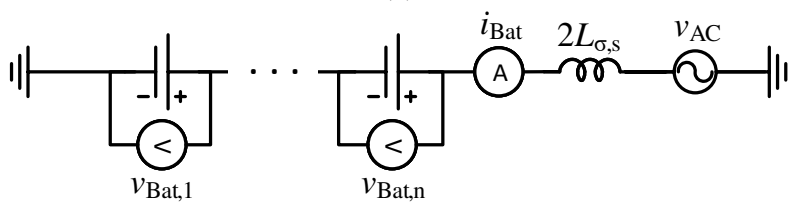

(b)

Fig. 9: (a) Rearrangement of CHB/MMSP multilevel inverter topology to apply an online impedance spectroscopy. (b) Electric scheme of impedance spectroscopy application.

the battery analyzer Gamry Reference 3000 [45]. The battery was mounted on a fixture to have a low contact resistance. The obtained impedances for a frequency range from $10 \mathrm{mHz}$ to $10 \mathrm{kHz}$ can be seen in Fig. 8(b). As can be seen, the impedance is highly dependent on the SOC. Nevertheless, around an SOC of about $50 \%$ the impedance deviation relative to the SOC is not that significant. Therefore, the impedance is often extracted only for the characteristic SOC of about $50 \%$ [6]. To determine the equivalent circuit parameters of the battery model a least square fit was used, considering three RC pairs, to match the impedance within a frequency range from $1 \mathrm{~Hz}$ to about $4 \mathrm{kHz}$. The obtained parameters can be seen in TABLE I and the impedance is plotted in red in Fig. 8(b). 


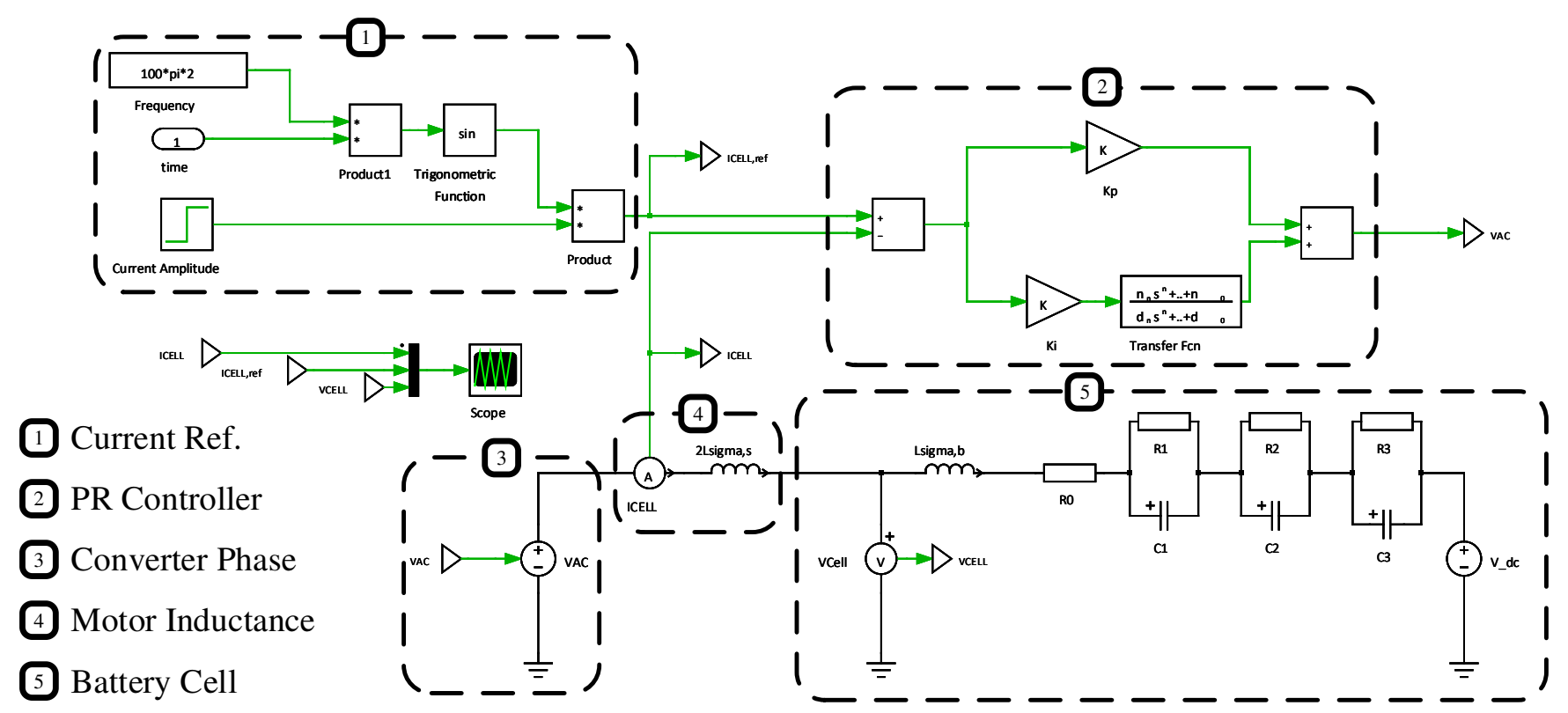

Fig. 10: Schematic implementation of a PR controller to conduct an on-board impedance spectroscopy.

In comparison to the parameter extraction in time-domain, the resistance $R_{0}$ is a bit smaller. This is due to the reason that the electric impedance spectroscopy considers a broader frequency range up to several $\mathrm{kHz}$, whereas the parameter extraction in time-domain, depending on the length of the current step, focuses rather on the low frequency range. As can be seen from Fig. 8(b), the real part of the impedance significantly increases when approaching $0 \mathrm{~Hz}$.

\section{B. Parameter Extraction using Impedance Spectroscopy by Converter Rearrangement and Utilization of Motor Inductance}

Considering the multilevel inverter or reconfigurable battery system topologies as shown in Figs. 1 and 2, an on-board impedance spectroscopy could be applied utilizing the motor inductance and a part of the inverter or reconfigurable battery system as a voltage source. For example, Fig. 9 shows the rearrangement of the CHB/MMSP multilevel inverter topology for a motor load in star-connection. If the motor would be operated in delta connection, the same principle could be applied, whereas the effective inductance value would become $0.667 L_{\sigma, \mathrm{s}}$ instead of $2 L_{\sigma, \mathrm{s}}$. As shown in Fig. 9, one phase could be used as dynamic voltage source to inject a sinusoidal current into the battery cells/modules of the neighboring phase's cells/modules. To properly control a sinusoidal current waveform, the utilization of the motor inductance is required. Figure 10 shows the schematic implementation of a proportional-resonant (PR) controller to conduct an on-board impedance spectroscopy. A PR controller, as described in [46], [47], has a controller gain as can be written according to

$$
F_{\mathrm{c}}(s)=K_{\mathrm{p}}+K_{\mathrm{i}} \frac{s}{s^{2}+\omega_{0}^{2}}
$$

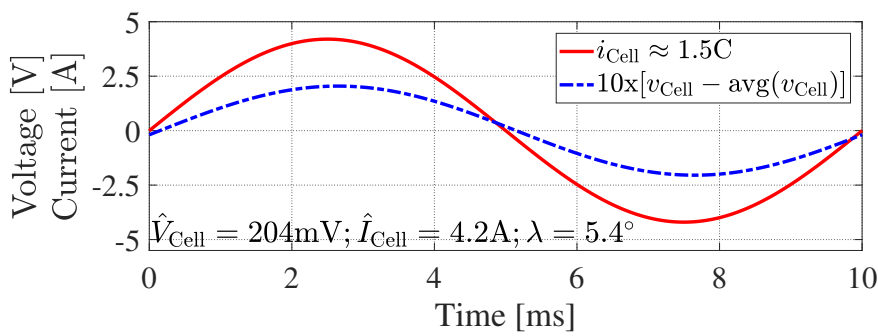

Fig. 11: Monitored battery cell current and voltage oscillation for the simulated impedance spectroscopy.

which is typically used to control sinusoidal current quantities tuned for a certain frequency. For a simulation, the battery parameters shown in TABLE I and Fig. 8(b) were chosen. Next, a part of the converter or RBS was simulated as a variable AC source to control a current of $1.5 \mathrm{C}$ and $100 \mathrm{~Hz}$ through the motor inductances $\left(2 L_{\sigma \mathrm{s}}\right)$, injected in one battery cell. Figure 11 shows the obtained battery voltage oscillation relative to the controlled current. Thus, the battery cell impedance for that specific can be calculated follows:

$$
\begin{gathered}
\bar{Z}_{\text {Cell }}=\frac{\hat{V}_{\text {Cell }}}{\hat{I}_{\text {Cell }}} e^{-j \lambda}=\frac{204 \mathrm{mV}}{4.2 \mathrm{~A}} e^{-j 5.4^{\circ}} \\
\bar{Z}_{\text {Cell }}=48.6 \mathrm{~m} \Omega e^{-j 5.4^{\circ}} \\
\bar{Z}_{\text {Cell }}=48.6 \mathrm{~m} \Omega\left[\cos \left(-5.4^{\circ}\right)+j \sin \left(-5.4^{\circ}\right)\right]
\end{gathered}
$$

and, finally,

$$
\bar{Z}_{\text {Cell }}=48.38 \mathrm{~m} \Omega-j 4.57 \mathrm{~m} \Omega .
$$

Comparing the obtained result in (21) with Fig. 8(b), it can be seen that correct impedance value is obtained. Sweeping the 
frequency of the injected current, such as shown in Fig. 8(b), and using least-square fit, the impedance can be determined for a broad frequency range.

\section{CONCLUSION}

Modular multilevel converter or reconfigurable battery systems offer a better utilization of the battery cells in comparison to a classical two-level inverter battery. In this manner, the actual battery life-time can be increased. However, the battery/cell monitoring and state estimation becomes more complex, but offers certain possibilities to localize and replace or bypass faulty battery cells. Therefore, this paper has been shown the novel application of two diagnostic approaches to determine the battery's cell/module impedance.

The first approach, a recursive time-domain parameter extraction, uses the balancing current between paralleled cells/modules, while monitoring the cell voltage. This approach has been experimentally validated. It can be applied even during the operation of the vehicle.

The second approach, rearranges the inverter topology so that a part of the converter can be used to conduct an electrochemical impedance spectroscopy at another part of the by controlling a sinusoidal current through the motor inductance. This method can be applied at standstill or halt.

For the application of either of the two approaches no additional hardware is needed and, thus, these could be easily implemented in any type of multilevel converter or RBS used for vehicle traction or variable speed drive applications.

\section{ACKNOWLEDGMENT}

The financial support provided by the Swedish Energy Agency is gratefully acknowledged.

\section{REFERENCES}

[1] A. Kersten, K. Oberdieck, A. Bubert, M. Neubert, E. Grunditz, T. Thiringer, and R. W. De Doncker, "Fault detection and localization for limp home functionality of three-level npc inverters with connected neutral point for electric vehicles," IEEE Transactions on Transportation Electrification, pp. 1-1, 2019.

[2] A. Bubert, S. Lim, and R. W. De Doncker, "Comparison of 2-level b6c and 3-level npc inverter topologies for electric vehicles," in 2017 IEEE Southern Power Electronics Conference (SPEC), Dec 2017, pp. 1-6.

[3] V. F. Pires, D. Foito, and J. F. Silva, "Fault-tolerant multilevel topology based on three-phase h-bridge inverters for open-end winding induction motor drives," IEEE Transactions on Energy Conversion, vol. 32, no. 3, pp. 895-902, Sep. 2017.

[4] F. Chang, O. Ilina, M. Lienkamp, and L. Voss, "Improving the overall efficiency of automotive inverters using a multilevel converter composed of low voltage si mosfets," IEEE Transactions on Power Electronics, vol. 34, no. 4, pp. 3586-3602, 2019.

[5] A. Kersten, E. Grunditz, and T. Thiringer, "Efficiency of active threelevel and five-level npc inverters compared to a two-level inverter in a vehicle," in 2018 20th European Conference on Power Electronics and Applications (EPE'18 ECCE Europe), Sep. 2018, pp. P.1-P.9.

[6] A. Kersten, M. Kuder, E. Grunditz, Z. Geng, E. Wikner, T. Thiringer, T. Weyh, and R. Eckerle, "Inverter and battery drive cycle efficiency comparisons of chb and mmsp traction inverters for electric vehicles," in 2019 21st European Conference on Power Electronics and Applications (EPE '19 ECCE Europe), Sep. 2019, pp. P.1-P.12.

[7] O. Josefsson, T. Thiringer, S. Lundmark, and H. Zelaya, "Evaluation and comparison of a two-level and a multilevel inverter for an ev using a modulized battery topology," in IECON 2012 - 38th Annual Conference on IEEE Industrial Electronics Society, Oct 2012, pp. 2949-2956.
[8] O. Josefsson, A. Lindskog, S. Lundmark, and T. Thiringer, "Assessment of a multilevel converter for a phev charge and traction application," in The XIX International Conference on Electrical Machines - ICEM 2010, Sept 2010, pp. 1-6.

[9] A. Acquaviva, A. Rodionov, A. Kersten, T. Thiringer, and Y. Liu, "Analytical conduction loss calculation of a mosfet three-phase inverter accounting for the reverse conduction and the blanking time," IEEE Transactions on Industrial Electronics, pp. 1-1, 2020.

[10] A. Bubert, K. Oberdieck, H. Xu, and R. W. De Doncker, "Experimental validation of design concepts for future ev-traction inverters," in 2018 IEEE Transportation Electrification Conference and Expo (ITEC), June 2018, pp. 795-802.

[11] A. Kersten, K. Oberdieck, J. Gossmann, A. Bubert, R. Loewenherz, M. Neubert, T. Thiringer, and R. De Doncker, "Measuring and separating conducted three-wire emissions from a fault-tolerant, npc propulsion inverter with a split-battery using hardware separators based on hf transformers," IEEE Transactions on Power Electronics, pp. 1-1, 2020.

[12] M. Kuder, A. Kersten, L. Bergmann, R. Eckerle, F. Helling, and T. Weyh, "Exponential modular multilevel converter for low voltage applications," in 2019 21st European Conference on Power Electronics and Applications (EPE '19 ECCE Europe), Sep. 2019, pp. P.1-P.11.

[13] O. Theliander, A. Kersten, M. Kuder, E. Grunditz, and T. Thiringer, "Lifep04battery modeling and drive cycle loss evaluation in cascaded h-bridge inverters for vehicles," in 2019 IEEE Transportation Electrifcation Conference and Expo (ITEC), June 2019, pp. 1-7.

[14] A. Kersten, O. Theliander, E. A. Grunditz, T. Thiringer, and M. Bongiorno, "Battery loss and stress mitigation in a cascaded h-bridge multilevel inverter for vehicle traction applications by filter capacitors," IEEE Transactions on Transportation Electrification, vol. 5, no. 3, pp. 659-671, Sep. 2019.

[15] A. Bessman, R. Soares, O. Wallmark, P. Svens, and G. Lindbergh, "Aging effects of ac harmonics on lithium-ion cells," Journal of Energy Storage, vol. 21, pp. 741-749, 2019.

[16] F. Helling, S. Götz, and T. Weyh, "A battery modular multilevel management system (bm3) for electric vehicles and stationary energy storage systems," in 2014 16th European Conference on Power Electronics and Applications, Aug 2014, pp. 1-10.

[17] S. Ci, N. Lin, and D. Wu, "Reconfigurable battery techniques and systems: A survey," IEEE Access, vol. 4, pp. 1175-1189, 2016.

[18] F. Chen, W. Qiao, and L. Qu, "A modular and reconfigurable battery system," in 2017 IEEE Applied Power Electronics Conference and Exposition (APEC), March 2017, pp. 2131-2135.

[19] W. Han, T. Wik, A. Kersten, G. Dong, and C. Zou, "Next-Generation Battery Management Systems: Dynamic Reconfiguration," IEEE Ind. Electron. Mag., 2020, accepted.

[20] X. Li and Z. Wang, "A novel fault diagnosis method for lithium-ion battery packs of electric vehicles," Measurement, vol. 116, pp. 402-411, 2018.

[21] D. Andre, C. Appel, T. Soczka-Guth, and D. U. Sauer, "Advanced mathematical methods of soc and soh estimation for lithium-ion batteries," Journal of power sources, vol. 224, pp. 20-27, 2013.

[22] X. Hu, D. Cao, and B. Egardt, "Condition monitoring in advanced battery management systems: Moving horizon estimation using a reduced electrochemical model," IEEE/ASME Transactions on Mechatronics, vol. 23, no. 1, pp. 167-178, Feb 2018.

[23] M. R. Jongerden and B. R. Haverkort, "Which battery model to use?" IET software, vol. 3, no. 6, pp. 445-457, 2009.

[24] M. Einhorn, F. V. Conte, C. Kral, and J. Fleig, "Comparison, selection, and parameterization of electrical battery models for automotive applications," IEEE Transactions on Power Electronics, vol. 28, no. 3, pp. 1429-1437, 2013.

[25] G. L. Plett, "High-performance battery-pack power estimation using a dynamic cell model," IEEE Transactions on vehicular technology, vol. 53, no. 5, pp. 1586-1593, 2004.

[26] B. Enache, E. Lefter, and C. Stoica, "Comparative study for generic battery models used for electric vehicles," in 2013 8TH INTERNATIONAL SYMPOSIUM ON ADVANCED TOPICS IN ELECTRICAL ENGINEERING (ATEE). IEEE, 2013, pp. 1-6.

[27] S. Skoog and S. David, "Parameterization of linear equivalent circuit models over wide temperature and soc spans for automotive lithium-ion cells using electrochemical impedance spectroscopy," Journal of Energy Storage, vol. 14, pp. 39-48, 2017. 
[28] A. Hentunen, T. Lehmuspelto, and J. Suomela, "Time-domain parameter extraction method for thévenin-equivalent circuit battery models," ieee transactions on energy conversion, vol. 29, no. 3, pp. 558-566, 2014.

[29] S. Skoog, "Parameterization of equivalent circuit models for high power lithium-ion batteries in hev applications," in 2016 18th European Conference on Power Electronics and Applications (EPE'16 ECCE Europe), Sep. 2016, pp. 1-10.

[30] Y.-H. Chiang, W.-Y. Sean, and J.-C. Ke, "Online estimation of internal resistance and open-circuit voltage of lithium-ion batteries in electric vehicles," Journal of Power Sources, vol. 196, no. 8, pp. 3921-3932, 2011.

[31] B. Fridholm, T. Wik, and M. Nilsson, "Robust recursive impedance estimation for automotive lithium-ion batteries," Journal of Power Sources, vol. 304, pp. 33-41, 2016.

[32] H. Blanke, O. Bohlen, S. Buller, R. W. De Doncker, B. Fricke, A. Hammouche, D. Linzen, M. Thele, and D. U. Sauer, "Impedance measurements on lead-acid batteries for state-of-charge, state-of-health and cranking capability prognosis in electric and hybrid electric vehicles," Journal of power Sources, vol. 144, no. 2, pp. 418-425, 2005.

[33] P. Mauracher and E. Karden, "Dynamic modelling of lead/acid batteries using impedance spectroscopy for parameter identification," Journal of power sources, vol. 67, no. 1-2, pp. 69-84, 1997.

[34] A. Zenati, P. Desprez, and H. Razik, "Estimation of the soc and the soh of li-ion batteries, by combining impedance measurements with the fuzzy logic inference," in IECON 2010 - 36th Annual Conference on IEEE Industrial Electronics Society, Nov 2010, pp. 1773-1778.

[35] R. Mingant, J. Bernard, V. S. Moynot, A. Delaille, S. Mailley, J.-L. Hognon, and F. Huet, "Eis measurements for determining the soc and soh of li-ion batteries," ECS Transactions, vol. 33, no. 39, p. 41, 2011.

[36] N. Li, F. Gao, T. Hao, Z. Ma, and C. Zhang, "Soh balancing control method for the mmc battery energy storage system," IEEE Transactions on Industrial Electronics, vol. 65, no. 8, pp. 6581-6591, Aug 2018.

[37] A. Lesnicar and R. Marquardt, "An innovative modular multilevel converter topology suitable for a wide power range," in 2003 IEEE Bologna Power Tech Conference Proceedings, vol. 3, 2003, pp. 6 pp. Vol.3-.

[38] D. G. Holmes and T. A. Lipo, Pulse width modulation for power converters: principles and practice. John Wiley \& Sons, 2003, vol. 18.
[39] K. Sharifabadi, L. Harnefors, H.-P. Nee, S. Norrga, and R. Teodorescu, Design, control, and application of modular multilevel converters for HVDC transmission systems. John Wiley \& Sons, 2016.

[40] M. Kuder, J. Schneider, A. Kersten, T. Thiringer, R. Eckerle, and T. Weyh, "Battery modular multilevel management (bm3) converter applied at battery cell level for electric vehicles and energy storages,' in PCIM Europe 2020; International Exhibition and Conference for Power Electronics, Intelligent Motion, Renewable Energy and Energy Management, 2020, pp. 1726-1733.

[41] B. Xiao, L. Hang, J. Mei, C. Riley, L. M. Tolbert, and B. Ozpineci, "Modular cascaded h-bridge multilevel pv inverter with distributed mppt for grid-connected applications," IEEE Transactions on Industry Applications, vol. 51, no. 2, pp. 1722-1731, 2015.

[42] K. Corzine and Y. Familiant, "A new cascaded multilevel h-bridge drive," IEEE Transactions on Power Electronics, vol. 17, no. 1, pp. 125-131, Jan 2002.

[43] A. Singer, F. Helling, T. Weyh, J. Jungbauer, and H. Pfisterer, "Modular multilevel parallel converter based split battery system $(\mathrm{m} 2 \mathrm{~b})$ for stationary storage applications," in 2017 19th European Conference on Power Electronics and Applications (EPE'17 ECCE Europe), Sep. 2017, pp. P.1-P.10.

[44] LG Chem, "Battery Cell - Product Description: ICR18650 C2 2800mAh," https://www.batteryspace.com/prod-specs/5702_5.pdf, (Accessed on 05/04/2019).

[45] Gamry Instruments, "Gamry reference 3000 - electrochemical measurement device," https://www.gamry.com/potentiostats/reference-3000/, (Accessed on 03/04/2020).

[46] R. Teodorescu, F. Blaabjerg, M. Liserre, and P. C. Loh, "Proportionalresonant controllers and filters for grid-connected voltage-source converters," IEE Proceedings-Electric Power Applications, vol. 153, no. 5, pp. 750-762, 2006.

[47] H. Cha, T.-K. Vu, and J.-E. Kim, "Design and control of proportionalresonant controller based photovoltaic power conditioning system," in 2009 IEEE Energy Conversion Congress and Exposition. IEEE, 2009, pp. 2198-2205. 